\title{
How middle level science teachers visualize and translate motion, scale, and geometric space of the Earth-Moon-Sun system with their students
}

\author{
Jennifer Wilhelm, ${ }^{1}$ Merryn Cole, ${ }^{2}$ Cheryl Cohen, ${ }^{3}$ and Rebecca Lindell ${ }^{4}$ \\ ${ }^{1}$ Department of Science, Technology, Engineering, and Math Education, University of Kentucky, \\ Lexington, Kentucky 40506, USA \\ ${ }^{2}$ Department of Teaching and Learning, University of Nevada Las Vegas, \\ 4505 S. Maryland Parkway, Las Vegas, Nevada 89154, USA \\ ${ }^{3}$ Department of Psychology, Governors State University, \\ 1 University Parkway, University Park, Illinois 60484, USA \\ ${ }^{4}$ Tiliadal STEM Education Solutions, 5 N 10th St Suite A-1, Lafayette, Indiana 47901, USA
}

(Received 10 May 2017; published 15 June 2018)

\begin{abstract}
[This paper is part of the Focused Collection on Astronomy Education Research.] We examined teachers' spatial-scientific reasoning and the alternative conceptions they held regarding Earth-space content. While participating in a professional development (PD) workshop, teachers engaged in an integrated mathematics and science project-based unit designed to foster spatial reasoning and improve lunar-related conceptual understanding. The Purdue Spatial Visualization Test-Rotation (PSVT-Rot) and the Lunar Phases Concept Inventory (LPCI) were used to assess understanding. We found the teachers held similar alternative conceptions as their students. Moreover, we discovered that teachers had limited understanding of the EarthMoon-Sun scale, motions, and geometric configurations. To determine how teachers' spatial-scientific confidence and ability translated to their classroom practice, we videotaped and analyzed instruction conducted by 6 teachers on an Earth-space lesson. Two teachers with the highest spatial-scientific confidence and ability had students achieving significant learning outcomes on both the PSVT-Rot and the LPCI.
\end{abstract}

DOI: 10.1103/PhysRevPhysEducRes.14.010150

\section{INTRODUCTION}

This research investigated alternative understandings held by middle level teachers (grades 6-8) concerning spatial-scientific, lunar-related concepts before and after they participated in focused professional development (PD). "Alternative understandings" refers to the explanations learners construct that are different than the accepted scientific explanation [1]. We define spatial-scientific concepts as those that refer to a learner's sense of scale and proportion, two- and three-dimensional (2D and 3D) visualization skills, perspective taking, and mental rotation. These abilities can influence their alternative understandings associated with astronomical concepts [2-5].

\section{SPATIAL REASONING IN THE SCIENCE DISCIPLINES}

But it is also widely acknowledged that spatial thinking is not fostered in our educational system and that

Published by the American Physical Society under the terms of the Creative Commons Attribution 4.0 International license. Further distribution of this work must maintain attribution to the author(s) and the published article's title, journal citation, and DOI. current practice depends more on selection of the most able students for spatially demanding disciplines than on fostering the spatial intelligence of all students [5].

A convincing body of research has documented the contribution of spatial reasoning skills to performance on STEM assessments and in disciplines like physics, engineering, and chemistry that require $2 \mathrm{D}$ and $3 \mathrm{D}$ visualization, mental rotation reasoning, and perspective taking [3,4,6-10]. Janelle et al. [5] call for more research on ways to foster spatial sense making for students so that the gated STEM community might be opened to all students. We argue that spatial reasoning skills are necessary for STEM teachers so that they might better understand the content they teach and thereby foster their students' spatial ways of thinking and knowing.

Astronomy and Earth-space science are STEM disciplines that are high in spatial cognitive demand. Black [10] argued that understanding the cause of lunar phases is not an easy Earth-space concept to realize since it involves the "movement of a half-lit body in space viewed from the unavoidable fixed position of Earth observers" (p. 10). Understanding Moon phases requires a well-developed spatial sense and perspective awareness as one notices and visualizes Earth and Moon orbital motions and their relative positions with respect to the Sun. Bower and 
Plummer [11] described how the field of astronomy requires the ability to constantly shift between reference frames to reconcile Earth- and space-based perspectives. Plummer, Bower, and Liben [12] linked spatial reasoning to children's understanding of the apparent motion of the Sun and for seasonal changes in constellations, recommending "that children-particularly those with lower perspectivetaking skills-may need additional support in learning to explicitly connect reference frames in astronomy" (p. 345). Al-Balushi [13] made similar recommendations based on evidence that 9th- and 10th-grade female students classified as low spatial learners tended to produce anthropomorphic mental images and add unnecessary details to Earth-space phenomena compared to the high spatial students. "To address this epistemological deficiency, the study recommends that techniques that enhance spatial ability should be used with low spatial ability learners to help them focus on the spatial arrangements of the phenomenon under study and eliminate unnecessary details" (p. 51).

A study investigating the mental models and imagery of basic astronomical phenomena (lunar phases, cause of seasons, etc.) held by teachers with science and nonscience training found that teachers' science backgrounds did not predict the scientific accuracy of their mental models and imagery [14]. Similar, incorrect mental models were held by all teachers in the study. According to Arslan et al. [14], “...there had been an expectation that science and physics preservice teachers had more scientific knowledge about astronomy topics than the rest, because of the relatedness of their departments. This, in fact, was not the case" (p. 107). Kanli [15] researched in-service physics teachers' and their students' astronomical content knowledge and discovered both groups possessed comparable alternative conceptions on topics concerning eclipses, Sun's energy, comets, and star rotations.

Two common alternative conceptions were found in Trumper's [16] study with in-service teachers' understanding of the cause of lunar phases. Sixteen percent of the teachers explained lunar phases were due to Earth's shadow cast upon the Moon and 29\% believed phases were caused by the Sun's shadow. Along with these alternative conceptions explaining lunar phases, other studies reported learners with a blocking notion mental model, that is, an object such as a cloud, celestial body, or "black space" blocks a portion of the Moon. Such alternative conceptions can be influenced by the learners' spatial reasoning sense where their mental models of the Earth-Moon-Sun system contain inappropriate scaling and celestial motions $[2,3,4]$.

According to the United States Next Generation Science Standards (NGSS), students should demonstrate understanding of Earth-space concepts by (a) developing or using a model of the Earth-Moon-Sun system to describe the cyclic patterns of lunar phases and (b) analyzing and interpreting data to determine scale properties of objects in the solar system [17]. These standards are intimately linked to the United States Common Core State Standards for Mathematics (CCSS-M) through the mathematical practices MP.2 (reason abstractly and quantitatively) and MP.4 (model with mathematics), as well as the standards 6.RP.A.1: Understand the concept of a ratio and use ratio language to describe a ratio relationship between two quantities and 7.RP.A.2: Recognize and represent proportional relationships between quantities [18].

Professional educators may fail to notice how to utilize and link the NGSS and CCSS-M standards and practices. This is especially true if teachers are trained in a single STEM discipline. Explicit activities for developing students' and teachers'spatial visualization and mental rotation abilities are one strategy for linking the NGSS standards and practices with the CCSS-M across the science and mathematics disciplines.

Some domain-specific spatial visualization constructs that are instrumental towards linking the standards and practices towards developing astronomical STEM content have been proposed by Wilhelm et al. [3,4]. These domain constructs are as follows: (a) geometric spatial visualization (GSV)-visualizing the geometric features of a system as it appears above, below, or within the system's plane; (b) spatial projection (SP)—projecting to a different location and visualizing from that perspective; (c) cardinal directions $(\mathrm{CD})$ - distinguishing directions $(\mathrm{N}, \mathrm{S}, \mathrm{E}, \mathrm{W})$ to document an object's vector position in space; and (d) periodic patterns (PP) - recognizing occurrences at regular intervals of time and/or space. Each of these domain constructs contains a mental rotation derivative especially evident when contextualized within an astronomical framework. GSV involves mental rotation since as one visualizes the Earth-Moon-Sun system, one must also consider and manipulate the motion of the system itself. SP has a mental rotation component since one must mentally maneuver the sky throughout a day's viewing due to Earth's rotation. In terms of CD, the Moon's vector direction (from an earthly perspective) continuously changes over time due to the Earth's rotation as well as the Moon's orbital motion. Finally, for PP, one must track and note the functional periodic relationship between percentage of lunar illumination (from an earthly perspective) and time while realizing these luminary changes are due to the Moon's orbital motion in the everchanging and continuously moving Earth-Moon-Sun system.

\section{SPATIAL-SCIENTIFIC CONFIDENCE AND ABILITY}

For our paper, the focus on confidence concerns teachers' reported spatial-scientific self-confidence levels acquired from content surveys and teachers' enacted spatial-scientific instructional decisions and actions gathered from videos of implemented classroom lessons and one-on-one interviews. More specifically, we define teachers' enacted spatialscientific confidence and ability in terms of teachers' explanations and instructional actions that either create or 
limit pathways for spatial ways of understanding scientific phenomena for themselves as well as their students. Our spatial-scientific context encompasses both how the teachers enact their lessons in their classroom environments as well as how teachers describe and model lunar phases. Student interaction relationships play a role in teachers' confidence in terms of how sure teachers are of the content during classroom discourse. A disconnect can occur where the teachers' observed spatial-scientific confidence and ability does not match their self-reported confidence and ability. And finally development and/or reconstruction of spatial-scientific confidence can be observed through experiences, interactions with others (researchers, students, other teachers), interactions with content, and time.

The following mixed methods study explored the relationship between teachers' spatial-scientific confidence and their ability to visualize and understand Earth-Moon-Sun geometries, scale, and motions within 2D and 3D spaces. We also investigated how well these teachers translated these spatial-scientific relationships within their instruction and how these translations influenced students' learning.

The questions guiding this research were as follows: (a) What spatial sense do middle level teachers possess with regard to mental rotation and visualization of 3D systems? (b) What alternative conceptions do middle level teachers hold concerning the scale and proportion of the EarthMoon-Sun system and the cause of lunar phases? (c) In what ways do teachers' spatial-scientific confidence and ability develop as a result of targeted professional development and how does this development impact their students' learning of Earth-space content?

Answers to these research questions can aid professional development educators in constructing appropriate experiences and instruction that will enable teachers to overcome their alternative beliefs and formulate accurate understandings of spatial-scientific concepts. Perhaps even more importantly, creating these instructional opportunities for teachers will strengthen and develop their enacted spatialscientific confidence as well as their self-confidence with the spatial-scientific material. In addition, teacher awareness of developing and emphasizing students' spatial thinking in their STEM classrooms could have an end effect of positively influencing their students' spatial-scientific confidence, ability, and STEM learning. This study is unique in that it details a research story that examined the trajectory from teacher professional development (PD) to implementation and student outcomes.

\section{METHODS AND PARTICIPANTS}

This mixed methods research study included 24 middle level mathematics and science teachers (21 females, 3 males) participating in a PD workshop aimed to enhance teachers' spatial and content knowledge and to create a project-based instructional experience with an Earth-space unit for teachers as learners. Teacher participants were recruited from four school districts and volunteered to engage in our PD and research study. Participants' years of teaching experience ranged from 0 to 28 . Eleven of the 24 teachers taught 6th grade (the grade in which lunar phases and ratio concepts are covered in the state) while the remainder taught grades $7-8$.

\section{A. Professional development overview}

During PD teachers engaged with the Realistic Explorations in Astronomical Learning (REAL) [19] project-based Earth-space unit. This project-based instruction (PBI) unit purposefully integrates middle school mathematics and science concepts. REAL is explicitly tailored to address alternative conceptions and to develop spatial reasoning skills (see Table I). The unit is designed to (a) foster learners' understanding of spatial scientific "big ideas" through the development of innovative projects, benchmark lessons, and virtual learning communities; (b) produce experiences for learners to "do mathematics" by challenging them to (i) analyze and represent situations graphically and geometrically, (ii) observe patterns and functional relationships to make astronomical predictions, and (iii) develop and employ spatial visualization skills to model and scale Solar System phenomena.

The PD began with 4 days of intense workshop experiences with REAL and continued with monthly meetings throughout the year using both face-to-face and virtual platforms. PD experiences included information and instruction on PBI curriculum, 2D and 3D modeling, and emphasis on investigative design and spatial reasoning (see Table I). Approximately 72 hours of PD occurred.

\section{B. Methods and data collection}

For the quantitative data collection, we used pre- and post-tests to determine teachers' understandings of lunarrelated concepts and spatial skills. Assessments included a Lunar Phases Concept Inventory (LPCI) [21,22], a 20-item multiple-choice survey which assessed eight science domains as well as four spatial domains (see Table II), and the Purdue Spatial Visualization Test-Rotation (PSVTRot) which was a 20-item multiple-choice instrument that assisted with diagnosing the level of teachers' mental rotation reasoning [23]. Descriptive statistical analysis was conducted with the LPCI and PSVT-Rot quantitative data. In addition to these quantitative assessments, a short survey of three questions concerning distance between Earth and the Moon and relative Earth-Moon diameter size was administered.

Our research also incorporated an embedded case study [24] where we included more than one subunit of analysis. One unit of analysis was the whole group of teachers (the descriptive data and short survey on the Earth-Moon scale) and our second unit of analysis was a group of 6th grade teachers who taught the REAL unit with their own students (data included descriptive statistics, scale survey, videotaped lessons, and three select interviews). Only 6th grade 
TABLE I. Lessons within the REAL unit [20].

Lesson 1 Can I see the Moon every night and why does it appear to change shape?-Students listen to the story, "Many Moons" and discuss the size, distance, and composition of the Moon as a group.

Moon journals - Students keep daily Moon observation journals for 5 weeks. Each day, students record the position (azimuth and altitude angle) of the Moon, sketch the shape of the Moon, and look for patterns in the appearance and position of the Moon.

Lesson 2 How do I measure the distance between objects in the sky? - Students learn to measure the distance between objects in the sky using their fists. They also use this method for estimating the position of the Moon in the sky.

Lesson 3 How can I say where I am on the Earth?-Students explore the concepts of latitude and longitude, including discussing where these angles come from and also how our position on the Earth affects where we see the Sun in the sky.

Lesson 4 How can I locate things in the sky? - Students use a sky map to locate stars, planets, and constellations in the sky. They draw each of these as they see them, then students measure the angular distance between stars in the sky.

Lesson 5 What are the global features of the Moon?-Students observe the major features of the Moon.

Lesson 6 What can we learn by examining the Moon's surface?-Students compare photos of the highlands and the mare on the Moon to determine the relative age of each, the crater density in each area, and to make an inference about what the early Solar System was like.

Lesson 7 What affects a crater's size? - Students brainstorm variables that affect a crater's size and then investigate one of these variables by making craters of their own. This lesson includes a discussion of independent and dependent variables and also graphing.

Lesson 8 The scaling Earth/Moon/Mars NASA Activity-Students use ratio and proportion concepts to better comprehend the size of the Universe by building a scale model of Earth, the Moon, and Mars using balloons.

Lesson 9 Moon finale-Students use foam balls and a light to discover the Earth-Moon-Sun geometries necessary to produce the phases of the Moon. Students are asked to refer to their Moon observation journals to check whether their geometry matches what was observed in nature.

TABLE II. Concept domains: LPCI science domains and corresponding spatial domains [4].

\begin{tabular}{|c|c|c|}
\hline \multicolumn{2}{|r|}{ LPCI scientific domains } & \multirow{2}{*}{$\frac{\text { Corresponding spatial domains }}{\text { Periodic patterns }(\mathrm{PP})}$} \\
\hline $\begin{array}{l}\text { A-Period of Moon's orbit } \\
\text { around Earth }\end{array}$ & B-Period of Moon's cycle of phases & \\
\hline $\begin{array}{l}\text { C-Direction of the Moon's } \\
\text { orbit around Earth }\end{array}$ & $\begin{array}{l}\text { E-Phase due to Earth-Moon-Sun } \\
\text { positions }\end{array}$ & $\begin{array}{l}\text { Geometric spatial visualization } \\
\text { (GSV) }\end{array}$ \\
\hline $\begin{array}{l}\text { D-Moon motion from earthly } \\
\text { perspective }\end{array}$ & $\mathrm{F}$-Phase location in sky-time of observation & Cardinal directions (CD) \\
\hline \multicolumn{2}{|c|}{$\mathrm{H}$-Effect of lunar phase with change in earthly location } & Spatial projection (SP) \\
\hline
\end{tabular}

teachers taught REAL since that was the grade level in which lunar phases is taught in the state. Eight of the eleven 6th grade teachers volunteered to teach the unit within their classrooms. Table III displays the research question, instrumentation utilized, and sample population.
Pre-tests were given on the first day of the PD workshop to the entire teacher group $(n=24)$. The summer workshop lasted three days, followed by one final late summer workshop day and then monthly one-day or half-day workshops throughout the academic school year. Post-tests

TABLE III. Research questions with corresponding data collection, instrumentation, and sample population.

\begin{tabular}{lc}
\hline \hline Research questions & Instrumentation \\
\hline $\begin{array}{l}\text { 1. What spatial sense do middle level teachers possess with } \\
\text { regard to mental rotation and visualization of } 3 D \text { systems? }\end{array}$ & $\begin{array}{c}\text { PSVT-Rot and LPCI administered to whole middle school } \\
\text { teacher group } \\
\text { 2. What alternative conceptions do middle level teachers hold } \\
\text { concerning the scale and proportion of the Earth-Moon-Sun } \\
\text { system and the cause of lunar phases? }\end{array}$ \\
$\begin{array}{l}\text { 3. In what ways do teachers' spatial-scientific confidence and } \\
\text { ability develop as a result of targeted professional }\end{array}$ & LPCI (teacher and student data); Survey on Earth-Moon scale, \\
$\begin{array}{l}\text { development and how does this development impact their } \\
\text { students' learning of Earth-space content? }\end{array}$ & $\begin{array}{l}\text { PSVT-Rot (teacher and student data); videotaped classroom } \\
\text { lessons (6th grade teacher focus group); Three select }\end{array}$ \\
\hline \hline
\end{tabular}




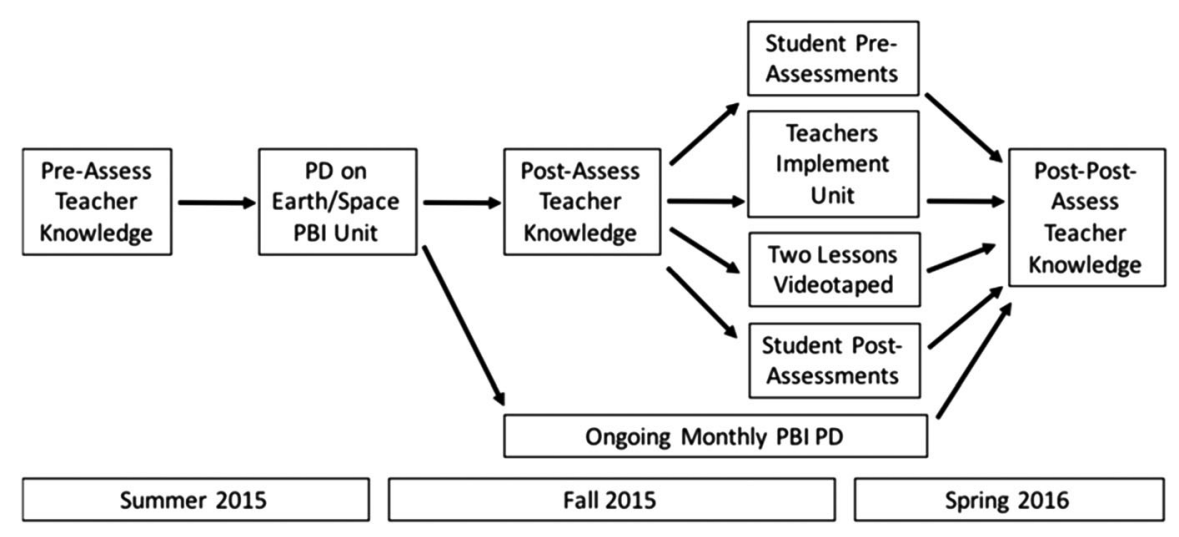

FIG. 1. Flowchart of data collection and professional development with teachers.

were given to all participants during the first academic school year workshop in September.

The 6th grade teachers $(n=8)$ who implemented the REAL unit were also given a post-post-test at the end of the academic year in April. Most of the eight teachers had either completed or nearly completed teaching the PBI unit with their own students by that time (hence the term postpost-test, since testing occurred post 6th grade unit implementation). We videotaped two lessons (lesson 2-How to measure the distance between objects in the sky and lesson 9-Moon finale) for each teacher during implementation of the unit. The Moon phase modeling lesson 9 was used to assess the degree to which the lesson enactment displayed teachers' spatial-scientific enacted confidence and ability. Student pre- and postassessment data (LPCI and PSVTRot) were also collected. Finally, we interviewed three of the 6th grade teachers at the end of the academic year. The purpose of the three interviews was to gain clarification about some of their LPCI survey responses. In order to gauge REAL unit enactment fidelity, teachers were asked to complete a short questionnaire about which lessons they implemented and any adaptations they made to the lessons. Figure 1 details the time points of data collection and professional development for the study.

\section{RESULTS}

\section{A. LPCI and PSVT-Rot results with all teachers}

Figure 2 displays the overall LPCI and PSVT-Rot pretest results and the LPCI results by spatial domain for all teacher participants, grouped 6th grade teachers, and grouped 7 th and 8 th grade teachers. Individual scores ranged from $20.00 \%$ to $95.00 \%$ on the overall LPCI and from $10.00 \%$ to $90.00 \%$ on the PSVT-Rot. Item analysis of LPCI results showed that teachers displayed alternative conceptions concerning the cause of lunar phases, including a "blocking" notion, the Sun's shadow explanation, and the Earth's shadow explanation. One-third of the teachers showed a scientifically accurate explanation (phase due to the Moon's position relative to the Earth), $41.70 \%$ held the
Earth's shadow explanation, $12.50 \%$ displayed the Sun's shadow explanation, and $12.50 \%$ chose an object-blocking notion. Of the eleven 6th grade teachers (grade in which topic is taught), $27.30 \%$ showed scientifically accurate explanations, $36.30 \%$ held the Earth's shadow explanation, $18.20 \%$ displayed the Sun's shadow explanation, and $18.20 \%$ chose the object-blocking notion. In terms of the LPCI spatial domains, teachers performed best on test items concerning periodicity (orbital, phases, etc. -5 total questions) with an average percent correct of $69.20 \%$ and with spatial projection (effect of lunar phase with change in earthly location - 4 total questions) with an average percent correct of $67.70 \%$. The next best domain performance was GSV (visualizing the Earth-Moon-Sun system above, below, or within the system's plane-7 total questions), see Fig. 2.

The most difficult items for teachers were those concerning cardinal direction (documenting the Moon's vector position in space-5 total questions) with an average percent correct of $36.70 \%$. Analysis of the LPCI test items revealed that not only did teachers not understand the cause of lunar phases, but they also had limited understanding of the apparent daily lunar motion (as a result of Earth's

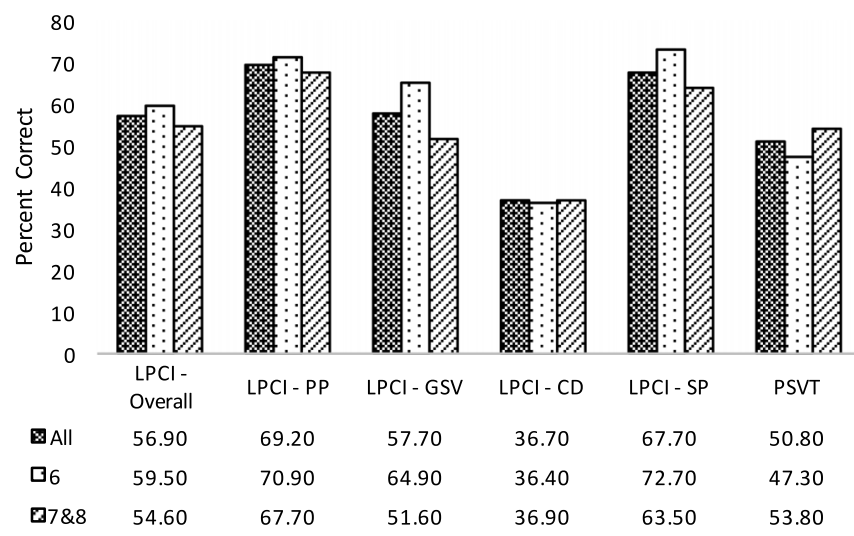

FIG. 2. LPCI (overall and by domain) and PSVT pre-tests percent correct for 6th grade teachers $(n=11)$ and 7 th-8th ( $n=13)$ grade teachers. 


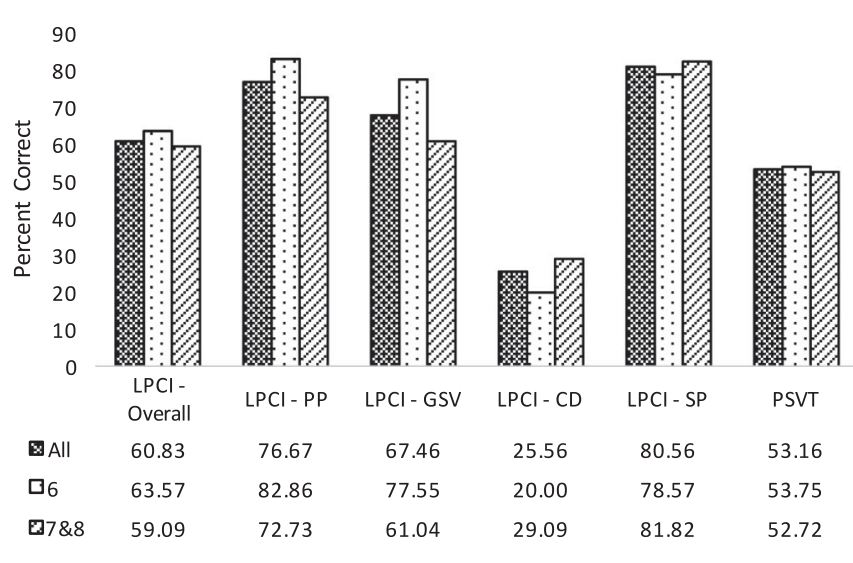

FIG. 3. LPCI (overall and by domain) and PSVT post-tests percent correct for 6 th grade teachers $(n=8)$ and 7 th-8th grade teachers $(n=11)$.

spinning on its axis) where the Moon rises in the East and sets in the West, and that each phase has different rise and set times. The average PSVT-Rot score was $50.80 \%$ correct on mental rotation ability.

Post-tests were administered during the beginning of the academic year. Average PSVT-Rot post scores showed $53.16 \%$ correct. For the post LPCI, similar to the pretests teachers performed best on test items concerning spatial projection with an average percent correct of $80.56 \%$ and periodicity with an average percent correct of $76.67 \%$ (see Fig. 3). As in the pre-LPCI, cardinal direction items were most difficult with an average percent correct of $25.56 \%$.

Item analysis of the LPCI showed $38.89 \%$ of teachers with a scientifically accurate explanation concerning causes of lunar phases, 38.89\% maintained an Earth's shadow explanation, $11.11 \%$ displayed the Sun's shadow explanation. No teacher had a lone object-blocking notion, but $5.56 \%$ had a mixed notion of the Sun's shadow and objectblocking to explain lunar phases. Another mixed notion showed 5.56\% with the Sun's shadow and the Earth's shadow explanation. For the 6th grade teachers, 28.6\% showed scientifically accurate explanations, $57.1 \%$ held the Earth's shadow explanation, and $14.3 \%$ displayed the Sun's shadow explanation.

\section{B. Short survey results for entire group}

On several short item response questions concerning Earth-Moon scale, the teachers reported Earth-Moon average distances ranging from 186000 miles to 3 light years (approximately 18 trillion miles); questions about relative Moon-Earth diameter sizes had $50 \%$ of the teachers correctly stating the Moon's diameter is roughly $1 / 4$ of the Earth's diameter (other responses included 1/100, 1/6, and $1 / 2$ Earth's diameter); and a question regarding the number of Earth diameters between the Earth and Moon had answers ranging from 1 to 500 (no one stated the correct response of 30). This survey was given during one of the benchmark lessons of the Earth-space unit during the summer PD. Teachers were not required to provide any identifiable information such as name or grade they teach.

By the time of the scale survey post-test (September 2015), half of the teachers correctly stated Earth-Moon distance, one-third correctly stated Moon-Earth diameter, and one-third correctly stated the number of Earth diameters between Earth and the Moon.

\section{Results for 6th grade teachers who implemented PBI unit}

Our second unit of analysis focused on the 6th grade teachers who proceeded to implement the project-based Earth-space unit with their own students after they had experienced the unit as learners for themselves. Eight of the original eleven 6th grade teachers comprised this group. Their years of teaching experience ranged from 2 to 28 years.

\section{Lunar Phases Concept Inventory}

Figure 4 reveals the results of the eight 6th grade teachers' LPCI pre, post, and post-post results. Their post-post-tests were given during the end of their academic year where each teacher had either completed or nearly completed the REAL unit with their own students. In all but one case (Teacher 5), 6th grade teachers either maintained $(95.00 \%$ correct) their pre-LPCI score by post-post-test time or increased their score relative to their prescore.

An analysis of the mean LPCI scores by domain for the eight teachers revealed a decrease in scores from pre to post for all domains except GSV (see Fig. 5). The decrease in the postscores was mainly due to one teacher (Teacher 2) who scored high on the pretest was not able to take the posttest. At least two additional PD days focusing on the REAL unit were conducted with these teachers after their posttesting to prepare them for teaching the unit with their students. Some taught the unit during the fall term while others taught the unit in late spring. The post-post-test was administered at the end of the spring term. The scores by domain (Fig. 5) show an increase in scores from pre- to

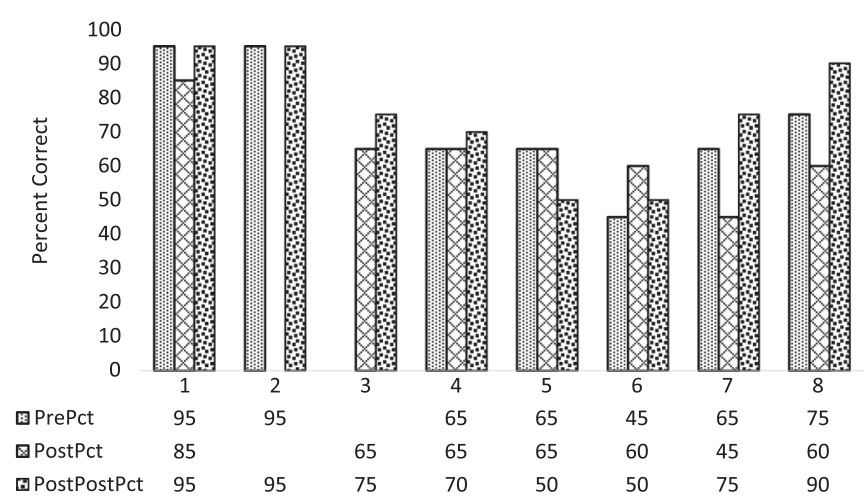

FIG. 4. Three snapshots (pre, post, and post-post) of LPCI percent correct by 6th grade teacher (teachers numbered 1-8). 


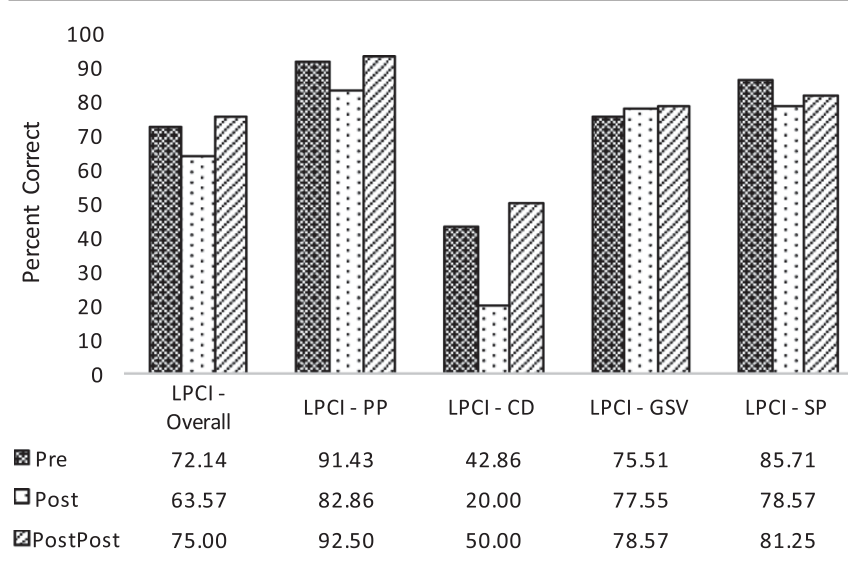

FIG. 5. Three snapshots (pre, post, and post-post) of percent correct of overall LPCI and by LPCI spatial domain for the eight 6th grade teachers who taught REAL.

post-post in all domains except SP. The largest domain increase was with CD items. This is particularly interesting when one compares the CD scores for the overall group's (6th, 7th, and 8th grade teachers shown in Figs. 2 and 3) pre- and post-CD scores, $36.70 \%$ and $25.60 \%$, respectively. In addition to this, years of research with students and preservice teachers has shown little to no gain on these items due to their difficulty $[3,4]$.

\section{Purdue Spatial Visualization Test-Rotation}

For the PSVT-Rot test that assesses teachers' mental rotation ability, teachers did not fare as well (see Fig. 6). In terms of pre to post (prior to their unit implementation), three teachers increased their scores, two maintained, one decreased, and one teacher was not present for the pretest. In comparing pre to post-post scores (of the seven that took the pre), three teachers increased their scores, two teachers maintained their scores, and two teachers decreased their scores. This assessment was particularly disliked by the teachers; according to their evaluations, the test was monotonous as they attempted to mentally rotate objects 20 times per test administration. This might explain their lackluster results.

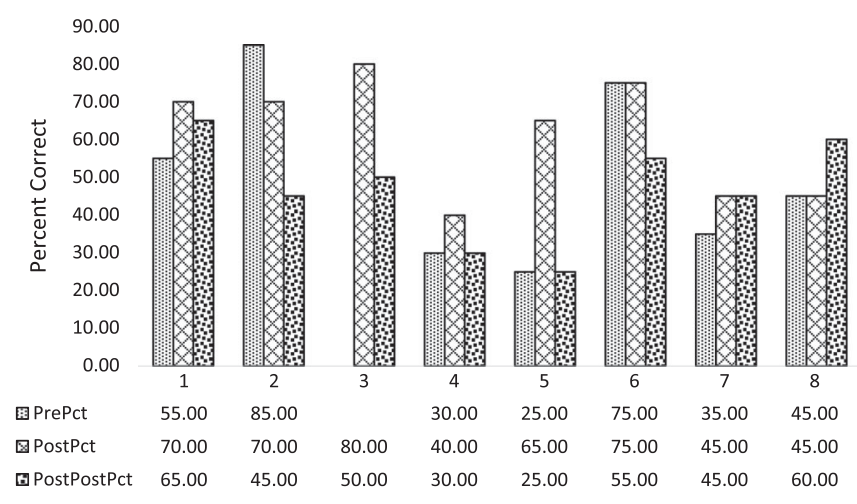

FIG. 6. Three snapshots (pre, post, and post-post) of PSVT-Rot percent correct by 6th grade teacher (teachers numbered 1-8).

\section{REAL implementation questionnaire}

As stated earlier, all teachers experienced as learners a PBI Earth-space unit (REAL) during their PD. REAL purposefully integrates mathematics and science embedded with spatial experiences (see Table III for REAL lessons). Teachers who implemented REAL in their own classrooms were asked to complete a questionnaire after implementation. The questionnaire asked which lessons were implemented, what changes, if any, were made, and to comment on any other lesson related feature.

Five of the teachers who implemented REAL completed the questionnaire. Most of the teachers implemented all of the REAL lessons similarly to the way they experienced them during their summer PD. One exception was Karen (teacher 5), who stopped after lesson 7, citing time as the reason she did not teach lesson 8 or the Moon finale (lesson 9 ). For those teachers who made adaptations, most involved the creation of student worksheets to record data. Three teachers modified the unit lessons to create differentiated instruction for students of various ability levels. Another common modification was on a scaling lesson (lesson 8), which asks students to create a scale model of the Earth, Moon, and Mars system using balloons. Four of the teachers chose not to use balloons as described in the lesson, with three using paper circles (using 2D models instead of 3D) and one teacher using Play-Doh.

\section{Teachers' spatial-scientific confidence and ability}

We videotaped two enacted lessons (lesson 2 and lesson 9) delivered by each 6th grade teacher. We analyzed the videotaped lunar phase modeling lesson (Moon finalelesson 9) to understand the enactment of each teacher's spatial-scientific confidence and ability. The classroom videos were coded for spatial-scientific confidence and ability based on if and how well the 6th grade teachers emphasized spatial domains, the way teachers used physical models, and the perceived confidence of the teachers in their spatial and lunar knowledge. (See Table IV for coded responses by teacher).

The first four possible letters in the spatial-scientific code are $\mathrm{G}(\mathrm{GSV}), \mathrm{S}(\mathrm{SP}), \mathrm{P}(\mathrm{PP})$, and $\mathrm{C}(\mathrm{CD})$. The presence of domain $\mathrm{G}$ may be demonstrated by asking students to consider the Earth-Moon-Sun system from above, below, or in the plane of the system. S may be enacted by the teacher through requesting students to consider how the phases might appear if the student were at different locations on the Earth, or from a changing perspective. $\mathrm{P}$ is represented in videos when repeating patterns of phases or motions are considered. $\mathrm{C}$ is enacted when students are asked to determine the direction one would need to look to find celestial or earthly objects from a given perspective.

We used the codes $i$ or $d$ to indicate if the teacher was using a model to learn $(i)$ or to confirm $(d)$. An example would be a teacher asking students to use their models to figure out where Earth and the Moon would have to be 
located to create a waxing crescent Moon phase from the perspective of Lexington, Kentucky and asking students how they know the model is in the correct position (coded $i$ ) versus a teacher asking students to place Earth in a straight line between the Sun and Moon to produce a full Moon phase ( $\operatorname{coded} d$ ).

Finally, + and - codes were used to denote the teacher's confidence in her own understanding of the spatial thinking and lunar phases content knowledge when leading the modeling lesson. A + was given if the teacher was able to take advantage of teachable moments productively and guide the students towards understanding the cause of the lunar phases using the models. A - was given if the teacher appeared to be following the lesson script, unable to deviate much if at all; this code was also given if teachable moments were ignored or only a superficial response was given before moving on. (See Table $\mathrm{V}$ for examples for teacher codes).

We coded three clips of each teacher's lesson 9. Throughout the lesson, as it was designed but not necessarily implemented, students use foam balls to represent Earth and the Moon and a lamp as the Sun. Students should refer to their Moon journals (see lesson 1 in Table I) to compare their model to the location and appearance of the Moon they observed over five weeks.

The first clip focused on students identifying Earthly reference points (i.e., Lexington, a city east of Lexington, North Pole, Equator, etc.). In this clip, teachers should request students to locate Lexington and a city east of Lexington using pushpins on the Earth model. The teacher should then ask students to determine how Earth rotates on its axis (clockwise or counterclockwise looking down on Earth's North Pole). The students should identify and use sunset and sunrise for the two marked locations on their model (Lexington and a city to the east) to make a claim and provide evidence for the direction of the rotation of Earth.

In the second clip teachers should begin by asking students to model a waxing crescent Moon. After students create their model, the teacher should stop them to make observations about each others' models and discuss how they can tell which one is correct. Teachers should direct students to their Moon journals, to see when and where in the sky they observed a waxing crescent Moon. Then, students should use this information to discover or confirm the correct Earth-Moon-Sun geometry for the waxing crescent phase.

In the final clip, near the end of the lesson, teachers should ask students to make a 2D representation (using paper and markers) of the Earth-Moon-Sun geometry for the first quarter Moon phase. Teachers should request students to identify how the Moon moves around Earth and what location the center of their circle for Earth would be on the globe (e.g., Are we looking down at the North Pole? The equator? Somewhere else on Earth?). Then, students should be asked to share drawings with the class and have a discussion about the accuracy of the representations and the perspective from which they were drawn.

All of the teachers who were videotaped teaching the Moon finale emphasized the GSV domain. For the most part, this meant that teachers asked students to model from a view above the plane of the Earth-Moon-Sun system. Amanda, Olivia, and Dawn also asked their students to observe the Moon phases from the Earth (within the plane). Olivia was the only teacher who explicitly mentioned the scale of any part of the system. Three of the teachers (Sarah, Dawn, Olivia) asked students to consider the viewpoint of different positions on Earth, emphasizing the SP domain. Only Dawn asked her students to look for patterns (PP), specifically patterns they saw in Moonrise and Moonset times for each phase. All of the teachers except Melanie touched on cardinal directions (CD) when beginning the modeling. Sarah and Dawn were both confident in their knowledge and took advantage of teachable moments throughout the lesson. While Amanda, Faith, and Olivia rated themselves as confident in their self-reported survey responses on the LPCI post-post-test, their enacted confidence and ability told another story. The three of them and

TABLE IV. Coded video analysis of spatial domain presence, model use, and confidence level by teacher. Note that neither Karen nor Misti enacted the lesson that was analyzed with the other teachers, resulting in no coding for enacted spatial-scientific confidence and ability.

\begin{tabular}{|c|c|c|c|c|c|c|c|c|}
\hline \multirow[b]{2}{*}{ Teacher } & \multicolumn{4}{|c|}{ Spatial domain } & \multicolumn{2}{|c|}{ Model use } & \multicolumn{2}{|c|}{ Confidence } \\
\hline & G (GSV) & $\mathrm{S}(\mathrm{SP})$ & $\mathrm{P}(\mathrm{PP})$ & $\mathrm{C}(\mathrm{CD})$ & $i$ & $d$ & + & - \\
\hline Sarah 1 & $X$ & $X$ & & $X$ & $\mathrm{X}$ & & $\mathrm{X}$ & \\
\hline Dawn 2 & $X$ & $X$ & $X$ & $X$ & $\mathrm{X}$ & & $\mathrm{X}$ & \\
\hline $\begin{array}{l}\text { Misti } 3 \\
\text { Melanie } 4 \\
\text { Karen } 5\end{array}$ & $\mathrm{X}$ & & & & & $\mathrm{X}$ & & $\mathrm{X}$ \\
\hline Faith 6 & $X$ & & & $X$ & & $X$ & & $\mathrm{X}$ \\
\hline Olivia 7 & $\mathrm{X}$ & $X$ & & $\mathrm{X}$ & $\mathrm{X}$ & & & X \\
\hline Amanda 8 & $\mathrm{X}$ & & & $\mathrm{X}$ & & $\mathrm{X}$ & & X \\
\hline
\end{tabular}




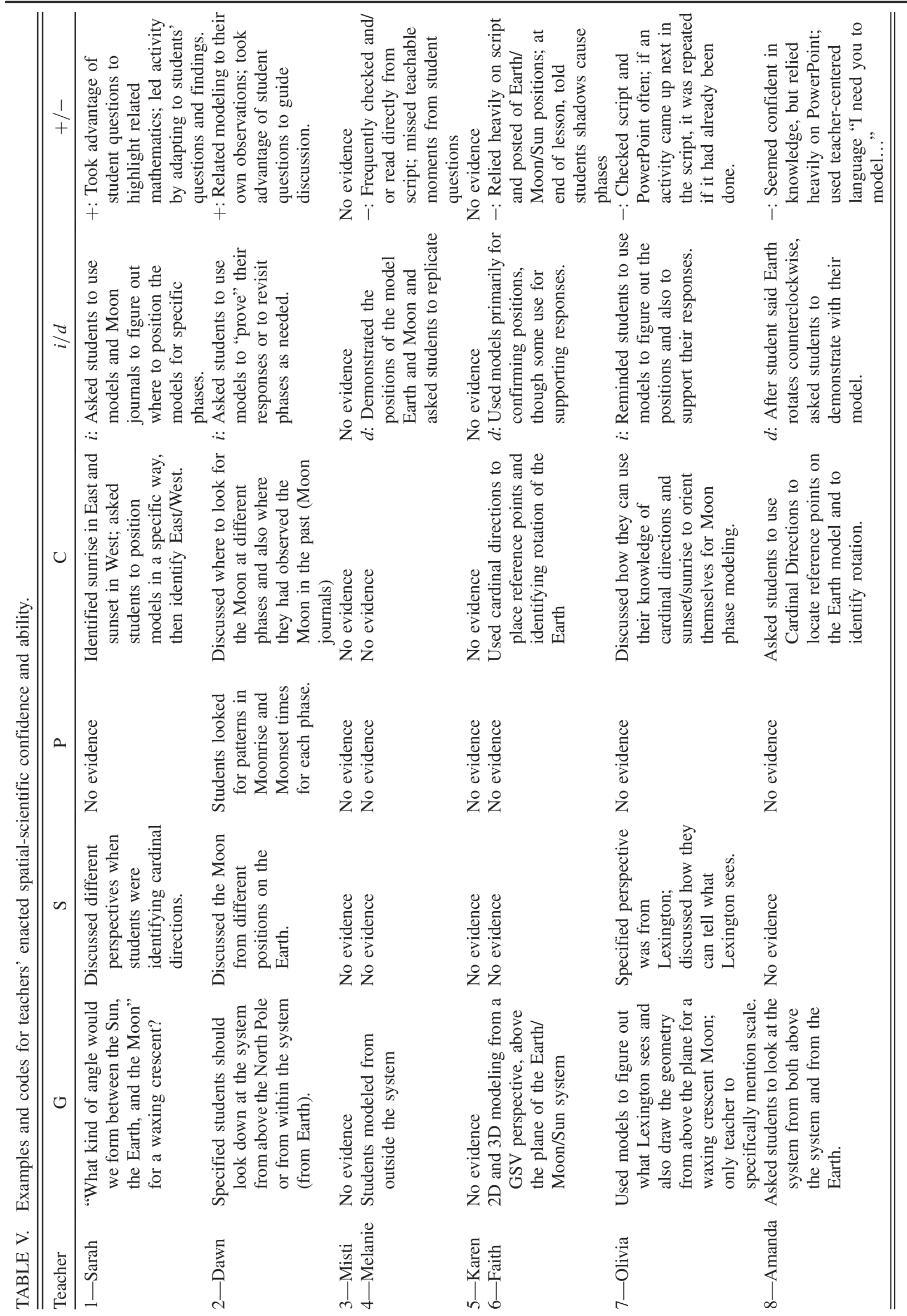


Melanie relied heavily on the script and missed teachable moments. Faith also told her students shadows cause the phases of the Moon, despite multiple students providing scientifically accurate explanations. Sarah, Dawn, and Olivia asked students to use their models to discover the geometries of Earth, the Moon, and Sun and also to provide evidence for their assertions. The other teachers (Melanie, Faith, and Amanda) instead emphasized placing the models in the correct positions, based on memory or instructions from the teacher.

In order to help confirm teachers' enacted confidence and ability, we also compared their self-reports regarding how confident they were in LPCI content answer choices pre, post, and post-post (see Table VI). While only Sarah (teacher 1) and Dawn (teacher 2) were coded + for confidence with their enacted spatial-scientific confidence and ability, multiple teachers expressed confidence on the LPCI. Only Melanie (teacher 4) and Karen (teacher 5) said they were not sure of their answers on the LPCI after implementing the unit in their own classrooms. Karen only implemented part of the unit, citing time as the reason she did not finish the unit with her students. Olivia (teacher 7) is an interesting case as her confidence slowly increased over the three time points of the LPCI, but her enacted lesson earned her a - (not very confident) code. Also, even though Amanda was confident in her responses at all time points for the LPCI, she also earned a - code for her spatialscientific code. These data show that regardless of the confidence teachers have (or not) about their understanding of the content, the enactment of their spatial-scientific confidence and ability may not match their own. The two teachers (Sarah and Dawn) who were coded + also expressed confidence in their LPCI responses. (See Tables V and VI).

\section{Follow-up interviews}

In closely analyzing the LPCI item responses of the eight 6th grade teachers' post-post-tests, we found that three of the teachers maintained a shadow alternative conception to explain the lunar phases. Two teachers (6-Faith and 7-Olivia) held an Earth's shadow conception and one teacher (5-Karen) held a Sun's shadow notion. In order to better understand how exactly they were thinking about these shadow notions, we interviewed each of these three teachers and coded each interview in a similar fashion as the enacted lessons.

Towards the beginning of the interviews, Author J. W. showed each teacher a photograph of a waxing crescent Moon and a waxing gibbous Moon. J. W. asked if they had seen the Moon look like either photo. All teachers had indicated seeing the Moon appear like the photos. Each was asked to explain why the Moon sometimes looked like the crescent shape and sometimes like the gibbous shape.

Olivia-2 years teaching experience. - Teacher 7 (Olivia) explained why we see the Moon appear in different shapes. She stated that it depended "on how it's orbiting around the Earth and in which direction the Sun's coming from." She (like all the teachers) was asked to sketch the configuration of the Earth-Moon-Sun for the waxing crescent and gibbous phases. As Olivia began to sketch, she stated "It's not going to be proportion." We assume that Olivia meant that she was not going to be able to draw it to scale. She was the only teacher that made sure to clarify that her representation would not be to scale (she also emphasized scale during her Moon finale implementation). Olivia's 2D representations (as viewed from space looking down upon the Earth's North Pole) of the configurations for a waxing crescent Moon phase and waxing gibbous Moon phase observed from an earthly perspective are shown in Fig. 7. Both configurations are correct. Olivia completed the rest of her interview without displaying any alternative conception.

Faith-3 years teaching experience. - When asked the same question, Teacher 6 (Faith) explained the reason for seeing the Moon's appearance change over time was based "on the position of the sky because during different phases, um, during the waxing phase it may...let me think...you may only see it from like 12 noon to midnight, where another one you may only be able to start seeing it at $9 \mathrm{pm}$ to 9 am. Because they're visible for 12 hours, but not always the same 12 hours." It is not completely clear what Faith meant by her statement "position of the sky." She

TABLE VI. Teacher confidence on LPCI. Note that teacher responses to LPCI question asking "In general, how confident are you that your answers to this survey are correct?"

\begin{tabular}{lllll}
\hline \hline & Teacher & \multicolumn{1}{c}{ Pre } & \multicolumn{1}{c}{ Post } & \multicolumn{1}{c}{ Post-Post } \\
\hline 1 & Sarah & Very confident & Very confident & Confident \\
2 & Dawn & Confident & N/A & Very confident \\
3 & Misti & N/A & Not sure & Confident \\
4 & Melanie & Confident & Not sure & Not sure \\
5 & Karen & Confident & Not sure & Not sure \\
6 & Faith & Confident & Not sure & Confident \\
7 & Olivia & Not at all confident & Not very confident & Confident \\
& Amanda & (just guessing) & Confident & Confident \\
\hline \hline
\end{tabular}




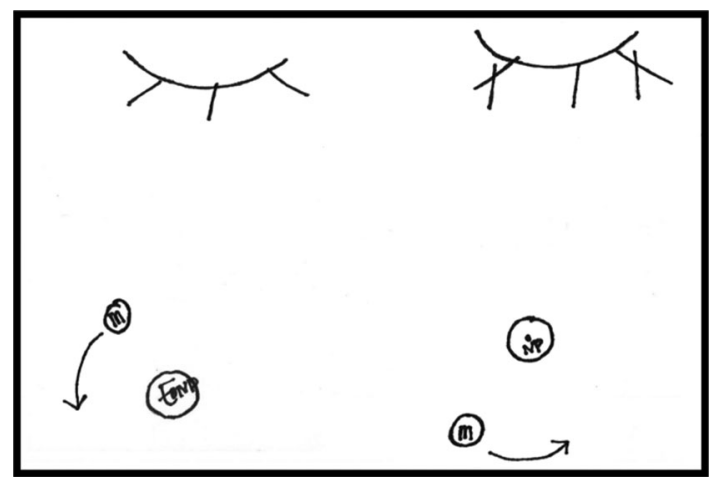

FIG. 7. Left-hand side: Olivia's Earth-Moon-Sun geometrical configuration for a waxing crescent Moon phase. Right hand side: Olivia's Earth-Moon-Sun geometrical configuration for waxing gibbous Moon phase. Moon (M); Earth (E), and North Pole (NP).

could have meant the Moon's orbital position or she could have been referring to the phase that corresponds with times that the Moon is visible in the sky. Her examples of noon to midnight would correspond with the first quarter phase (a waxing phase) and $9 \mathrm{pm}$ to 9 am would correspond with waning gibbous.

Figure 8 shows Faith's Earth-Moon-Sun configuration for waxing crescent and gibbous phases. In her configuration, the small circles between the Sun and Earth represent the crescent phase and small circles to the right of Earth represent the gibbous phase. The two circles for each phase were due to her trying to make the drawing appear more three dimensional (her final Moons were the ones closest to the words new and full). The following excerpts explain the perspective of the drawing.

Faith: So, this would be a New Moon or Full Moon, New Moon (She pointed to different spots, then labeled them

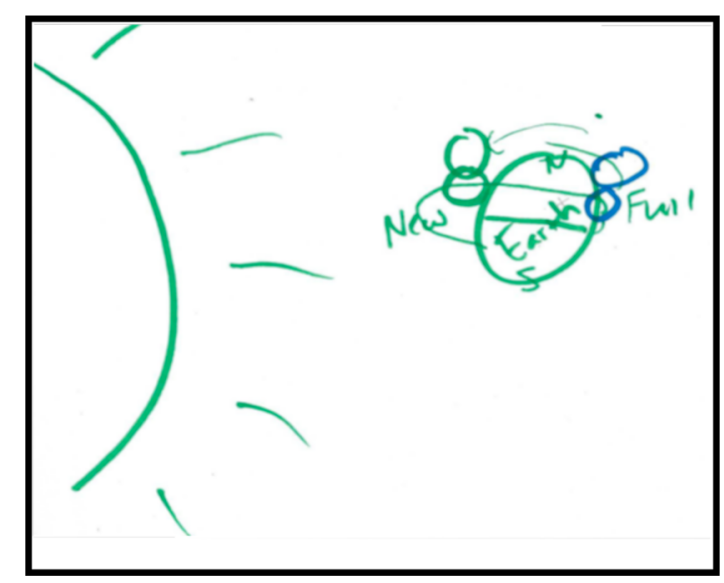

FIG. 8. Faith's Earth-Moon-Sun geometrical configuration for a waxing crescent Moon phase (circles between Sun and Earth) and waxing gibbous Moon phase (small circles near "Full"). She indicated a lunar orbit that circles the equator in a counterclockwise direction if observed from above the Earth's North Pole.
Full and New). It would be about here. (She placed the first circle that has a small gap between the Moon and Earth representing the waxing crescent Moon phase, see Fig. 8, and then adjusted her placement with a second green circle).

Interviewer: Ok, so, I want to make sure I understand. Before I ask any more questions, if I were in outer space and I landed right there (Interviewer pointed to the center of the circle drawn to represent the Earth) where would I have landed?

Faith: This is like the Equator right there (Faith drew a line across the Earth to represent the Equator).

Interviewer: This is the Equator?

Faith: Yeah, this would be the North Pole (labeled N for North Pole) and South Pole (labeled S for South Pole) and it would kind of orbit like that. (Faith motioned an orbital path with her fingers illustrating the Moon emerging out of the paper between the Sun and Earth and then into the paper by where she labeled a Full Moon.

Both representations drawn by Faith and Olivia can be considered accurate (although not to scale). Faith's would be accurate if she were attempting (with her 3D drawing) to have the waxing crescent phase positioned out of the paper left of the Earth and the waxing gibbous also out of the paper to the right of the Earth. However, shortly after she generated her representation on paper, she was asked to model the waxing crescent Moon phase three dimensionally with foam balls to represent the Earth and Moon and a light source to represent the Sun. Faith created a waxing crescent lunar phase by casting the Earth's shadow upon the Moon thus displaying the alternative conception and did not match her 2D representation.

Karen-24 years teaching experience. - Karen (Teacher 5) explained the reason for the different phases was due to the Moon's "rotating and revolving around the Earth and we see different phases, but also if you could be in a different spot in the world...because it will look different. I mean it'll be the same phase (gesturing with hands), but it could be turned up". We believe that Karen was referring to one of the lessons in the Earth-space unit that utilized Stellarium (free planetarium software). In this lesson, comparisons were made between Northern and Southern Hemisphere viewings of various lunar phases. For example, a first-quarter Moon phase from a Northern perspective would show the Moon illuminated on the right-hand side while a Southern perspective would have the first-quarter phase illuminated on the left-hand side.

Karen's representation of the Earth-Moon-Sun configuration for the waxing crescent and gibbous Moon phases is shown in Fig. 9. The small circle immediately to the right of the Sun is her waxing crescent moon and the other small circle (right of the Earth) is her waxing gibbous. The large full circle is Earth and the vertical line represents the Equator. She incorrectly illustrated the lunar orbit as 


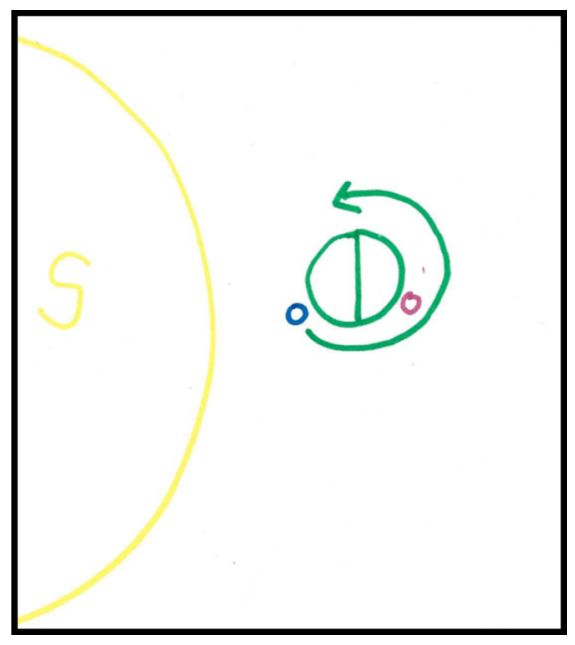

FIG. 9. Karen's Earth-Moon-Sun configuration for waxing crescent and waxing gibbous Moon phase positions with a large circular Earth that has one of Earth's poles facing the Sun.

revolving around the Earth's poles. She never indicated whether or not she was trying to make a three dimensional representation; that is, she did not motion with her fingers an orbit coming in or out of the paper. In addition to this, she placed one of the Earth's poles (did not label North or South) closest to the Sun.

Later in the interview, Karen was asked to model the geometry of a first-quarter Moon phase in three dimensions where she was the Earth, a foam ball was the Moon, and a light source was the Sun. Karen proceeded to place the Sun to her back and the Moon to the front. She moved the Moon around until she cast her shadow on the Moon in just such a way that it was half lit on the right-hand side.

Interviewer: Ok, and so the reason we're seeing it half lit is because why?

Karen: Oh, and you know the Earth is on a tilt too.

Interviewer: Ok, so why are we seeing only half of it lit? Karen: Um, because it's... in its relationship... to the... to the sun.

Interviewer: Ok, but I'm saying so, so this part I can see is lit but that part's not lit (pointing at the foam ball). Why is that part not lit?

Karen: Right. Because that's in the shadow.

Interviewer: Of what?

Karen: Of the... I'm Earth?

Interviewer: Yeah, you're Earth.

Karen: Um... the Earth's shadow?

Interviewer: Ok. So then did you mean to have that as a response on your test? (Karen chose Sun's shadow as a response to why we see a first quarter Moon phase on the LPCI.)

Karen: Yes.

Karen was the remaining teacher that had chosen a Sun's shadow to explain why we sometimes see a first quarter Moon phase. Right before the episode shown here, Karen correctly modeled the New Moon phase placing the Moon between the Earth and Sun. But when asked where the Full Moon phase would need to be located, she stated that the Moon would need to be placed on the other side of the Sun (in other words Moon, Sun, and Earth in a straight line configuration with Sun in the middle). It remained unclear exactly what was meant by the Sun's shadow notion.

Interview summary. - The follow-up interviews shed light on the understandings that these 6th grade teachers held even after (or towards the completion of) implementing the Earth-space REAL unit. Olivia correctly described the cause of lunar phases and did not display any alternative notions throughout the rest of the interview even though at least one of her answers on the LPCI displayed an Earth's shadow alternative conception. Coding the interviews in a similar fashion as the lessons, Olivia earned a GC + for enacted spatial-scientific confidence and ability due to her explanations, domain display, and accuracy and confidence $(+$ or -$)$.

Faith first mentioned the periodicity of the Moon's visability throughout a day's time. She did not initially display an Earth's shadow alternative conception when generating her paper representation of the Earth-Moon-Sun geometrical configurations for the waxing crescent and gibbous lunar phases. However, she later illustrated an alternative understanding as she modeled a waxing crescent phase (using foam balls and a light source) by casting Earth's shadow upon the foam Moon in a similar manner to Karen's first-quarter Moon modeling. We coded Faith's enacted confidence and ability as GP-. The negative was due to inaccuracy in her geometric spatial visualization 3D modeling.

Finally, Karen's responses illustrated that she continued to display a shadow alternative conception, although it is not clear whether it is an Earth's shadow or a Sun's shadow notion. Some of her spatial pitfalls concerned understanding exactly the orbital motion and path of the Moon and her limited ability to project herself both inside (SP) and outside (GSV) the Earth-Moon-Sun system. Her spatialscientific confidence and ability was coded as GS-.

\section{Student learning outcomes by teacher}

Student learning outcomes for the LPCI and the PSVTRot assessments by teacher are shown in Table VII. Students of all but two teachers (teachers 5 and 6) had significant learning gains on the LPCI. Teacher 5 (Karen) and teacher 6 (Faith) were teachers that displayed lower spatial-scientific confidence and ability as evidenced by their LPCI scores and interviews, as well as Faith's classroom video data.

For the PSVT-Rot, teachers 1, 2, 4, and 5 displayed overall (boys and girls combined) significant gain scores. Teachers 2 and 4 showed boys with significant gains and teachers 2 and 7 showed girls with significant gain scores. 
TABLE VII. Students' percentage correct gain scores on LPCI and PSVT-Rot by teacher. Note that gains are calculated by post-pre. Significance determined by repeated measures ANOVA.

\begin{tabular}{|c|c|c|c|c|c|c|c|c|}
\hline $\begin{array}{l}\text { Teacher } \\
\text { self-confidence } \\
\text { pre-post-post }\end{array}$ & $\begin{array}{c}\text { Teacher } \\
\text { enacted-confidence } \\
\text { and ability }\end{array}$ & Group & LPCI $N$ & $\begin{array}{l}\text { LPCI } \\
\text { gain }\end{array}$ & $\begin{array}{c}\text { LPCI } \\
\text { partial } \eta^{2}\end{array}$ & $\operatorname{PSVT} N$ & $\begin{array}{l}\text { PSVT } \\
\text { gain }\end{array}$ & $\begin{array}{c}\text { PSVT } \\
\text { partial } \eta^{2}\end{array}$ \\
\hline \multirow[t]{3}{*}{ All } & & All & 395 & $15.30^{\mathrm{c}}$ & 0.49 & 339 & $4.66^{b}$ & 0.07 \\
\hline & & Males & 162 & $14.29^{c}$ & 0.45 & 137 & $4.89^{b}$ & 0.06 \\
\hline & & Females & 233 & $15.99^{c}$ & 0.52 & 202 & $4.50^{\mathrm{c}}$ & 0.09 \\
\hline \multirow[t]{3}{*}{ 1-Sarah VC-C } & $\mathrm{GSC} i+$ & All & 66 & $16.97^{\mathrm{c}}$ & 0.63 & 60 & $5.34^{\mathrm{a}}$ & 0.09 \\
\hline & & Males & 29 & $15.00^{\mathrm{c}}$ & 0.60 & 25 & 5.40 & 0.08 \\
\hline & & Females & 37 & $18.51^{\mathrm{c}}$ & 0.66 & 35 & 5.29 & 0.10 \\
\hline \multirow[t]{3}{*}{ 2-Dawn C-VC } & GSPC $i+$ & All & 70 & $15.72^{\mathrm{c}}$ & 0.47 & 67 & $6.2^{\mathrm{c}}$ & 0.19 \\
\hline & & Males & 30 & $16.84^{\mathrm{c}}$ & 0.48 & 29 & $7.75^{\mathrm{b}}$ & 0.31 \\
\hline & & Females & 40 & $14.88^{\mathrm{c}}$ & 0.47 & 38 & $5.00^{\mathrm{a}}$ & 0.12 \\
\hline \multirow[t]{3}{*}{ 4-Melanie NS-C } & $\mathrm{G} d-$ & All & 73 & $18.09^{c}$ & 0.58 & 59 & $5.85^{\mathrm{b}}$ & 0.13 \\
\hline & & Males & 30 & $19.66^{\mathrm{c}}$ & 0.63 & 27 & $10.55^{\mathrm{b}}$ & 0.26 \\
\hline & & Females & 43 & $16.97^{\mathrm{c}}$ & 0.55 & 32 & 1.88 & 0.03 \\
\hline \multirow[t]{3}{*}{ 5-Karen C-NS } & Interview (GS-) & All & 20 & 8.00 & 0.17 & 22 & $10.91^{\mathrm{a}}$ & 0.25 \\
\hline & & Males & 10 & 3.00 & 0.04 & 11 & 15.00 & 0.32 \\
\hline & & Females & 10 & 13.00 & 0.34 & 11 & 6.82 & 0.20 \\
\hline \multirow[t]{3}{*}{ 6-Faith C-C } & $\mathrm{GC} d-$ Interview $(\mathbf{G P}-)$ & All & 66 & $5.84^{\mathrm{b}}$ & 0.17 & 49 & -1.03 & 0.00 \\
\hline & & Males & 23 & 1.08 & 0.01 & 13 & -8.08 & 0.09 \\
\hline & & Females & 43 & $8.37^{\mathrm{c}}$ & 0.31 & 36 & 1.48 & 0.01 \\
\hline \multirow[t]{3}{*}{ 7-Olivia JG-C } & GSC $i-$ Interview $(\mathbf{G C}+)$ & All & 71 & $19.36^{\mathrm{c}}$ & 0.62 & 59 & 4.83 & 0.06 \\
\hline & & Males & 29 & $17.93^{\mathrm{c}}$ & 0.67 & 23 & -0.43 & 0.00 \\
\hline & & Females & 42 & $20.36^{\mathrm{c}}$ & 0.60 & 36 & $8.20^{\mathrm{b}}$ & 0.21 \\
\hline \multirow[t]{3}{*}{ 8-Amanda C-C } & $\mathrm{GC} d-$ & All & 29 & $20.00^{\mathrm{c}}$ & 0.67 & 24 & 2.08 & 0.02 \\
\hline & & Males & 11 & $19.09^{\mathrm{b}}$ & 0.59 & 10 & -1.50 & 0.01 \\
\hline & & Females & 18 & $20.55^{\mathrm{c}}$ & 0.74 & 14 & 4.64 & 0.10 \\
\hline
\end{tabular}

\section{DISCUSSION}

Upon examining the survey results, one might conclude that since teachers had difficulty visualizing the EarthMoon scale, this could explain some of their low prescores on the LPCI as suggested by Fanetti [2]. Mental rotation is also key in visualizing the Earth-Moon-Sun system and its motions. If spatial ability and mental rotation are necessary, then these skills must be developed. Prior studies $[3,4,9]$ conducted with 6 th grade students who experienced the project-based REAL curriculum showed significant development of their spatial and mental rotation skills from pre to post intervention. Pretests given to these 6th graders had students exhibiting similar alternative conceptions to the teachers in our study. In pondering these alternative conceptions, one can imagine how learners might visualize an Earth's shadow idea to explain phases-especially if they believe that there is only one Earth diameter between the Earth and Moon. But what about the object blocking notion? What object is doing the blocking? And what exactly is the Sun's shadow explanation? Do students (and teachers) think that the Sun's shadow is cast upon the Moon to create phases or do they think that the Sun is causing a shadow to be cast from another entirely different object?

The follow-up teacher interviews assisted in better understanding some of these alternative notions held by teachers. Faith (teacher 6) displayed correct geometric Earth-Moon-Sun orientations for various phases with her 2D representation, but then resorted to an Earth's shadow orientation for a waxing crescent phase when modeling in 3D. Faith's students showed only small LPCI significant gain scores. Karen (teacher 5) was the only teacher to maintain a Sun's shadow notion where at one point when modeling lunar phases in three dimensions, she placed the Sun between the Moon and Earth. In addition to this, it was unclear in what ways Karen understood the Moon's orbital path. Her 2D representation had the Moon orbiting the poles with one Earth pole facing the Sun. Karen never completed a Moon finale (lesson 9) with her students. She cited time as her reason for not implementing, but another reason could be due to her acceptance that she was confused and did not feel comfortable or confident with the 2D and 3D lunar phase modeling. In terms of Karen's students' learning outcomes, no LPCI significant gains 
were observed; however, her students' PSVT-Rot scores did significantly improve. Olivia (teacher 7) displayed no alternative conceptions during her interview and when modeling in two dimensions correctly noted her representation was not to scale. Her students achieved significant LPCI learning outcomes (second highest gains in the teacher group) and her female students made significant PSVT-Rot gain scores.

Teachers in our study participated as learners as they engaged in the REAL PBI unit. PD with the 6th grade teachers $(n=11)$ was especially crucial since only $27.30 \%$ held scientifically accurate understandings on LPCI questions concerning the cause of lunar phases on the pretest and this was material that had to teach to their students. In REAL lesson 8, the teachers created a scale model of Earth, Moon, and Mars using balloons. Several of our teachers struggled with calculating the model diameters of the Moon and Mars and the model distances between the bodies. These calculations required the use of the same ratio and proportional relationships that appear in the 6th grade mathematics standards [18]. Creating these integrated mathematics-science lessons embedded with spatial experiences displayed how to tie the NGSS and CCSS-M together in productive and beneficial ways. Such experiences help to strengthen one's spatial-scientific confidence and ability.

Teachers in our overall whole group study (6th, 7th, and 8th grade teachers) had similar scores pre and post on the LPCI (56.90\% to $60.83 \%)$ and pre and post on the PSVTRot (50.80\% to $53.16 \%$ ). In terms of alternative conceptions, the blocking notion no longer appeared as an LPCI response on the post-test and the number of Earth's shadow and Sun's shadow explanation choices to explain lunar phases decreased by the time of the post-test. In addition, we found more reasonable postresponses concerning EarthMoon distance and scale.

For our embedded case study, the eight 6th grade teachers increased (though not statistically significantly) their LPCI and PSVT-Rot scores from pre to post-post (72.0\% to $75.0 \%)$ and (55.0\% to $65.0 \%)$, respectively. We examined teachers' confidence levels at multiple time points (pre, post, post-post) and found some teachers that thought they understood the Earth-space content came to understand what they did not know and grappled with making sense of the Earth-Moon-Sun system in 2D and 3D spaces. Such self-reflection and struggles showed time point self-confidence going from confident to not sure. Other teachers who admitted to being not sure and just guessing on LPCI pretests flourished in the PBI environment and PD experiences as they made their way through the spatial-scientific content first as learners and then as facilitators of learning with their own students.

Teachers like Dawn and Olivia (teachers 2 and 7, respectively) showed increases in their self-confidence and evidence of strong spatial-scientific enacted confidence and ability (Dawn within her lesson and Olivia within her interview; see Table V). Both of these teachers' students' LPCI learning outcomes resulted in significant increases (Table VII). Two teachers (Sarah and Dawn) with the highest spatial-scientific confidence and ability had students achieving significant learning outcomes on both the PSVT-Rot and the LPCI. The highest LPCI student gain scores were with teachers 7 and 8, Dawn and Amanda, respectively. Both also selected either very confident or confident with the LPCI spatial-scientific content by the post-post time point. We argue that our findings show that it is not enough to conduct PD with teachers. Teachers also need to implement what they learned during their PD with their own students in order to really advance their content knowledge as well as their spatial-scientific confidence and ability. Evidence of this emerges in the pre to post LPCI teacher scores (slightly decreasing) and the pre to post-post LPCI increasing scores (though insignificant).

\section{CONCLUSION AND SIGNIFICANCE}

Perhaps the greatest contribution of this research study is the importance of teachers' enacted spatial-scientific confidence and ability development as well as their selfconfidence with spatial-scientific materials towards the advancement of students' spatial science learning. One can only imagine what Faith's students were thinking during Faith's enacted Moon finale lesson when they were providing correct explanations of the cause of lunar phases and she said the phases were due to shadows. This was an interesting example because if Faith had any doubt in her content knowledge, she could have made this a wonderful teachable moment (for herself and her students) to determine who was correct via phase modeling. While students play a role in a teacher's enacted confidence and ability, the teacher can only change if they have even the slightest awareness that they may not know all the answers. Even with Faith's imposement of the shadow alternative conception to explain phases in her REAL lesson, her students showed some significant gains (girls only) on the LPCI, but these scores were lower than the other teachers who had well-developed spatial-scientific confidence and ability.

What teachers chose to emphasize in their lessons (resulting in part of their enacted spatial-scientific code) is quite interesting too, in that we do not know why teachers left out certain spatial domains or even key parts of the Moon Finale lesson. Were those parts omitted because the teacher was uncomfortable with the material? We would argue that this was the case with Karen. We highly suspect the discomfort with the material played a major role in the Moon finale lesson not happening with her students. Or perhaps some lesson parts were omitted because the teachers did not think they were as important as other things during the lesson. For instance, consider the $i / d$ code; did the teachers choose to demonstrate the phases because they thought that a diagram was sufficient enough for learning compared to taking the time for the students to 
explore, grapple, and figure it out on their own? Were students permitted the opportunity for an "Ah Ha!" moment, or were they simply told an answer to record on their worksheet? PD should include not only an opportunity for teachers to experience the lessons as learners themselves but also discussion on how and/or why the lesson was designed as it was. This discussion could help teachers understand which parts of the lesson are essential, enabling the teachers to make more informed decisions when adapting lessons for their classrooms.

The implication is that while we have been able to draw parallels between the teachers' enacted confidence and ability and students' learning, we need more information on the teachers' spatial-scientific self-confidence in order to better understand (i) why teachers enacted the lesson the way they did, and (ii) how teachers' self-confidence influences student learning. We also found that a teacher's spatial-scientific confidence and ability is not necessarily fixed in time, but can evolve as they engage with others (students, teachers, etc.), with materials (models, 2D and
3D spaces), and their reflective self to mindfully visualize and translate spatial ways of knowing and understanding scientific phenomena.

Finally, we call for future studies that examine instructional choice and the need for PD to be carefully designed for not only content knowledge development, but also pedagogical content knowledge where teachers become more aware of their own misconceptions and learn to plot pathways to knowing difficult scientific concepts. Challenging science topics like the cause of lunar phases need special emphasis on spatial relationships, perspectives, and pathways for students to truly visualize, grasp, and understand. Recommendations for productive PD that we gathered from our study are as follows: (i) teachers need 2D and 3D spatial-scientific experiences as learners, (ii) teachers need the opportunity to enact lessons with their own students and reflect on their enactment, (iii) teachers need the opportunity to grapple with difficult subject material, share their struggles in a safe environment, and feel empowered to admit what they do not know.
[1] L. Danaia and D. H. McKinnon, Common alternative astronomical conceptions encountered in junior secondary science classes: Why is this so?, Astron. Educ. Rev. 2, 32 (2008).

[2] T. Fanetti, master's thesis, Iowa States University [Ames, IA, 2001 (unpublished)].

[3] J. Wilhelm, Gender differences in lunar-related scientific and mathematical understandings, Int. J. Sci. Educ. 31, 2105 (2009).

[4] J. Wilhelm, C. Jackson, A. Sullivan, and R. Wilhelm, Examining differences between preteen groups' spatialscientific understandings: A quasi-experimental study, J. Educ. Res. 106, 337 (2013).

[5] D. G. Janelle, M. Hegarty, and N. S. Newcombe, Spatial thinking across the college curriculum: A report on a specialist meeting, Spatial Cogn. Comput. 14, 125 (2014).

[6] R. R. Hake, Relationship of individual student normalized learning gains in mechanics with gender, high-school physics, and pretest scores on mathematics and spatial visualization, Physics Education Research Conference, Boise, Idaho, 2002, http://www.physics.indiana.edu/ hake/PERC2002h-Hake.pdf.

[7] S. A. Sorby, Developing 3D spatial skills for engineering students, Australaian J. Eng. Educ. 13, 1 (2007).

[8] S. M. Al-Balushi, A. S. Al-Musawi, A. K. Ambusaidi, and F. H. Al-Hajri, The effectiveness of interacting with scientific animations in chemistry using mobile devices on grade 12 students' spatial ability and scientific reasoning skills, J. Sci. Educ. Technol. 26, 70 (2017).

[9] C. Jackson, J. Wilhelm, M. Lamar, and M. Cole, Gender and racial differences: Development of sixth grade students' geometric spatial visualization within an Earth/space unit, School Sci. Math. 115, 330 (2015).
[10] A. A. Black, Relationship of earth science misconceptions and conceptual understandings with three types of spatial abilities in university non-science majors, Proceedings of the National Association for Research in Science Teaching (NARST) (National Association for Research in Science Teaching, Vancouver, Canada, 2004).

[11] C. Bower and J. Plummer, The role of spatial perspectivetaking in understanding celestial motion, Proceedings of the National Association for Research in Science Teaching (NARST) (National Association for Research in Science Teaching, Baltimore, Maryland, 2016).

[12] J. D. Plummer, C. A. Bower, and L. S. Liben, The role of perspective taking in how children connect reference frames when explaining astronomical phenomena, Int. J. Sci. Educ. 38, 345 (2016).

[13] S. Al-Balushi, The nature of anthropomorphic mental images created by low and high spatial ability students for different astronomical and microscopic scientific topics, Int. J. Sci. Soc. 4, 51 (2013).

[14] A. S. Arslan and U. Durikan, Pre-service teachers' mental models of basic astronomy concepts, Sci. Educ. Int. 27, 88 (2016).

[15] U. Kanli, Using a two-tier test to analyse students' and teachers' alternative concepts in astronomy, Sci. Educ. Int. 26, 148 (2015).

[16] R. Trumper, A cross-college age study of science and nonscience students' conceptions of basic astronomy concepts in preservice training for high-school teachers, J. Sci. Educ. Technol. 10, 189 (2001).

[17] NGSS Lead States, Next Generation Science Standards: For States, by States (National Academies Press, Washington, DC, 2013). 
[18] National Governors Association Center for Best Practices and the Council of Chief State School Officers, Common Core State Standards (National Governors Association, Washington, DC, 2010).

[19] J. Wilhelm and R. Wilhelm, Realistic explorations in astronomical learning, curriculum developed at Texas Tech University (2007).

[20] M. F. Lamar, J. A. Wilhelm, and M. Cole, A mixed methods comparison of teachers' lunar modeling lesson implementation and student learning outcomes, J. Educ. Res. 111, 108 (2018).
[21] R. Lindell and J.P. Olsen, Developing the Lunar Phases Concept Inventory, Proceedings of the Physics Education Research Conference, 2002, Boise, ID (AIP, New York, 2002).

[22] R. S. Lindell, Ph. D. thesis, University of Nebraska, Lincoln, AAT, 3022646 (2001).

[23] G. M. Bodner and R. B. Guay, The Purdue visualization of rotations test, Chemical Educator 2, 1 (1997).

[24] R. K. Yin, Case Study Research, Design and Methods, 3rd ed. (Sage Publications, Newbury Park 2003). 